\title{
A proposal for the annual appraisal of, and developmental support for, General Practitioners with a Specialist Interest (GPwSIs) in respiratory medicine
}

\author{
Steve Holmes*, Kevin Gruffydd-Jones \\ for the General Practice Airways Group (GPIAG) Education \\ Sub-Committee ${ }^{1}$
}

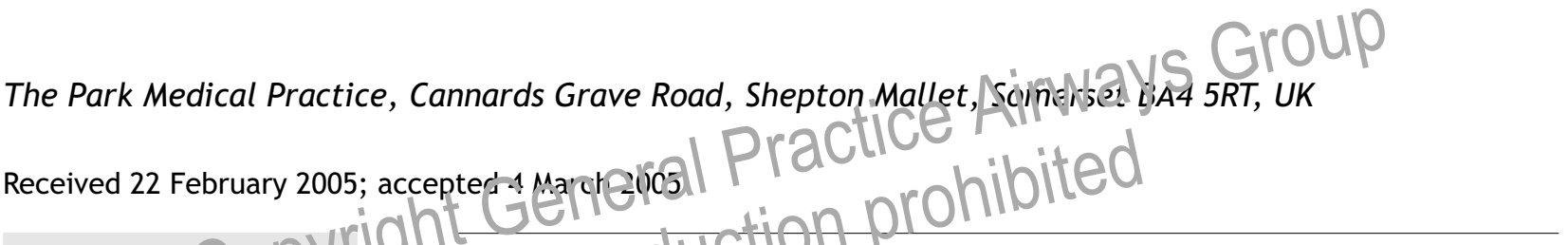

KEYWORDS

GP appraisal;

GPwSI;

Respiratory medicine;

Developmental support;

Education

Suminary $G_{\text {his }}$ paper provides best practice recommendations for the appraisal o1, and developmental support for, GPwSIs in respiratory medicine. These recommendations are closely linked with the current system for quality-assured National Health Service (NHS) general practice appraisal in the United Kingdom (UK). The recommendations are based on Department of Health guidance, and follow consultation with a range of relevant professional bodies involved in respiratory care and professional development. We describe the Primary Care Organisation (PCO) responsibilities, training issues, support systems, and documentation required to ensure that appraisal for GPwSIs in respiratory medicine meets national standards. In addition we address links to NHS general practitioner (GP) appraisal, revalidation, and documentation from the General Medical Council (GMC) on good medical practice. Developmental support that will complement and be sensitive to the needs of the GPWSI in respiratory medicine is described, as well as the ideal situation for educational support for practitioners, and the need for variability of appraisal dependent upon the GPwSI's experience. This appraisal and support system will allow general practice, NHS managers and the public to have confidence that those GPwSIs working in respiratory medicine will provide high quality care.

(c) 2005 General Practice Airways Group. Published by Elsevier Ltd. All rights reserved.
\end{abstract}

* Corresponding author. Tel.: +44 1749 334383; fax: +44 1749334393.

E-mail address: steve.holmes@btinternet.com (S. Holmes).

1 GPIAG, Edgbaston House, 3 Duchess Place, Edgbaston, Birmingham, B168NH, UK. Tel.: +44 1214 548219; fax: 441461207819 , Email: info@gpiag.org. Website: http://www.gpiag.org. 


\section{Introduction}

This paper, providing proposals for annual appraisal of, and developmental support for, GPwSls in respiratory medicine, is based on concepts that have been supported by the Department of Health concerning appraisal [1], continuing professional development [2] and GPwSI roles [3,4]. These proposals have been tested and amended in consultation with members of the GPIAG, the National Association of Primary Care Educators (NAPCE), the NHS Modernisation Agency, and the British Thoracic Society (BTS), along with several independent physicians with an interest in professional development.

We suggest that this model would be equally applicable to other GPwSI roles or practitioners with a specialist interest, following adaptation in consultation with the relevant specialist interest groups and experts in that specialist area.

This paper does not discuss the place of performance management of the GPwSI, nor is it concerned with management targets or monitoring. We consider that performance management and elements of clinical governance, including regular audit of activity, should be an integral part of the internal processes implemented by primary (a) organisations (PCOs) when employ in a la PwsI, compatible with good hum ai rescurces (HR) advice.

The role of arpraise! wil! be dicousedurinst, followed by recommendations tor the developmental support of the GPwSI.

\section{Appraisal of the GPwSI in respiratory medicine}

\section{Aim of GPwSI appraisal}

The Department of Health defined appraisal as "a formative and developmental process. It is about identifying development needs, not performance management. It is a positive process, to give GPs feedback on their past performance, to chart continuing progress and identify development needs" [1]. In the same document it was recommended that "the content of appraisal will be based on the GMC's core headings set out in the 'Good Medical Practice' document'. We follow this guidance and suggest that the process of appraisal for a GPwSI should closely follow the appraisal for other GPs in the NHS.

\section{Link to NHS GP appraisal}

All GPs are expected to undertake an NHS GP appraisal annually. Many GPs have a variety of more specialised roles, and usually trained NHS appraisers will appraise and support the GP concerned appropriately. This is sufficient for many GPs who have special interests. However, our recommendation for specialised appraisal is based on the specialist nature of the respiratory GPwSI role. There are unlikely to be local appraisers who have understanding of this role in detail, or the way in which role development of respiratory GPwSIs is occurring elsewhere around the UK.

It is assumed that the NHS GP appraisal will form the clear basis for any revalidation process and that the GPwSI appraisal is not an alternative route. The GPwSI appraisal allows more time for reflection on, and development of, the specialised role, and the documentation from the specialised appraisal would constitute part of the GP's annual NHS appraisal.

Following discussion, particularly within the GPIAG, we recommend that a GPWSI in respiratory medicine should have good PCT support in other areas, as well as specialised appraisal on a regular basis, at least annually.

The appraiser will be expected to work with the GPwSI to highlight dearining arid developmental needs and will he ro to provide pointers in addressing these. This should be seen as part of an on-going progranime of E- :- inued professional development as GUSgescea by the GMC and should link into the process of revalidation [5].

\section{Documentation}

We recommend that the basis for documentation is based on standard documentation in keeping with Good Medical Practice [6] and other NHS GP appraisal forms [7], in order to "ensure that information from a variety of NHS employers will be recorded and expressed consistently" [1]. These standard appraisal forms do vary in the different countries of the UK but are clearly based on the same underlying principles and are adaptable to the needs of the GPwSI [8]. The standard documentation can be easily modified to make it specifically relevant to the role of the GPwSI, in keeping with recommendations made following the fifth report of the Shipman Inquiry [9] and in keeping with the proposed Chief Medical Officer review (expected publication October 2005).

\section{Appraiser attributes, training and quality assurance}

The Department of Health advice in 2002 stated that "the appraiser should be another GP, who 
will have been properly trained in carrying out appraisal. The assessment of some of the more specialist aspects of a GP's clinical performance should be carried out by peers who are fully acquainted with the relevant areas of expertise and knowledge"' [1]. We support this assertion.

Thus, a GPwSI appraiser requires the following attributes:

1. good understanding of appraisal skills and support skills [10]

2. good ability to relate to the GPwSI role in respiratory medicine

3. good understanding of the specialist respiratory field in which the doctor works

4. good knowledge and contacts to be able to signpost the GPwSI to others with experience at a regional or national level

The GPIAG will organise appropriate training for interested practitioners in order to support the GPWSI programme in respiratory medicine around the UK. The training will be in line with national recommendations. It will be expected that after successful and satisfactory completion of appraisal training the GPwSI will participate in national or local networks for appraisers which will offer ongoing training, audit and support. The GPIAG will also ensure that appraisers have undertaken adequate annual updating, th d that the system for feedback on appo is es s' performance is adequate in order to quality-assure the $p$ cees. in tine with other NHS organisations [12,13].

\section{Specialist appraiser register}

The number of trained appraisers will need to increase to ensure adequate numbers are available to meet the demand of rising numbers of GPwSls, whilst ensuring that GPwSI appraisers undertake sufficient appraisals to maintain their competence.

It is recommended that the GPIAG hold a register of GPs with a specialist interest in respiratory medicine who have undergone training and maintained skills (to national standards) in appraisal of GPwSls in respiratory medicine. This would allow the GPwSI, in discussion with the GPIAG appraisal contact, to choose an appropriate appraiser from the current appraisal list.

\section{Potential needs of GPwSIs in respiratory medicine}

Gruffydd-Jones [14] suggests, in the recently published proposal for accreditation of GPwSls in respiratory medicine, that three key areas are likely to form the basis of the role of the GPwSI. These three areas are:

1. to provide a leadership and co-ordinating role for respiratory services within a PCO

2. to provide specialist "intermediate care" clinical services

3. to promote education and training in respiratory medicine within a PCO.

These are the key areas where a GPwSI would require appraisal, support and advice. It is recognised that the relative mix of these three roles will vary depending on the GPWSI role undertaken. The three areas correlate to the core GMC areas [6] and to the key areas addressed in NHS GP appraisal [7].

Key areas addressed in NHS GP appraisal (with key GPwSI areas underlined) are:

- Good clinical care

- Maintaining good medical practice

- Relationships with patients

- Working with colleagues

- Teaching and training $\mathrm{C}$

- Probity

Niv hasement (Service Development and Leader-

ship)

Research

Health

\section{Appraisal process}

The GPwSI appraisal process should follow a similar outline to NHS GP appraisal, in that the appraisee completes appropriate forms, the interview takes place in a formative and developmental fashion, and the appraisee and the appraiser produce an agreed Summary Form 4 . The Form 4 would usually be expected to be incorporated into the NHS GP appraisal, and would form a good basis for a specialised professional development plan (PDP) along with recommendations for development of the GPwSI service.

\section{Frequency of meetings}

It is recommended that appraisal meetings should occur annually, with an on-going supportive relationship including at least a brief 6-month contact. In certain circumstances, depending on the GPwSI role undertaken and the level of the GPwSI's experience, the appraisal may be required at shorter or longer intervals. 


\section{Developmental support for the GPwSI in respiratory medicine}

One of the key outcomes from NHS GP appraisal is a personal PDP; the same would apply following GPwSI appraisal. We now present a proposed system to provide developmental support for the GPWSI in respiratory medicine.

\section{Aim of developmental support}

A variety of educational and developmental roles are described in the literature $[15,16]$. Teachers, tutors, coaches, mentors and supervisors are commonly used terms. Within the health care environment the roles identified have often been confused $[15,16]$. For the purposes of avoiding this confusion we have used the term 'developmental supporter' to indicate the person or persons providing support aimed at enhancing the performance of the GPwSI. The developmental supporter will usually use a variety of educational and developmental skills within their role.

The aim of developmental support for the GPwSI is to maximise the GPwSI's impact in the provision of respiratory care. It should be specific to the needs of the practitioner and De flexislecenough to work with the learnirs style of the practitioner. Often the aprobicte cevelopmenta' sopert can be defined tnrough the appraipal sy.tem.

\section{Developmental supporters for GPwSls}

The support can be provided by a variety of expert resources. The terminology behind roles of mentors, tutors, trainers, facilitators, coaches and teachers can be confusing - between organisations and between educationalists, managers and clinicians in the NHS. Pragmatically, we have used the term 'developmental supporter' as one which covers the range of people providing developmental educational facilitation that should help to enhance and support the performance of the GPwSI.

It is envisaged that clinical support will probably be from one of the local secondary care respiratory specialists (adult respiratory or paediatric), but this could be another GPwSI in respiratory medicine. Support for the GPwSI in their education and leadership roles could come from other experienced health professionals in these fields (for example, PCO professionals, medical educationalists, or NHS managers). In specifying the requirements of the support needed it will be seen that the person best suited to provide the developmental support role will vary depending upon the GPwSI specialist role undertaken. It is likely that support may be required from primary care, secondary care or indeed a mix of the two. It is recommended, in accordance with NHS practice [11], that the developmental supporter and appraiser are not the same person.

\section{Frequency of meetings with supporter(s)}

It is recommended that the support provided is specific to identified needs and will, by necessity, vary according to these needs. We do, however, recommend that a proportion of time for development is arranged on a regular basis. This may involve attendance at joint clinics, e-mail or phone discussion, educational meetings, or other contact.

We recommend that at least six half-day sessions per annum should be contractually set-aside for educational updating and developmental support. We also recommend that at least two sessions should be joint sessions with a secondary care respiratory consultant, which will enhance specialist skills and help to develop the primary-secondary care interface. It is recognised thara Griss Dho works relatively few sessions faray spend a relatively large persenta; of bf their time on education-especially if an organisation's mandatory training is included. Howere, the spectalist knowledge and skills of the GPivs need to be maintained commensurate with the position held, and this should be considered for every appointment of a GPWSI in respiratory medicine.

\section{Funding of appraisal and support}

Estimates from other work on appraisal suggest that an average of eight hours is required in order to prepare for, and to undertake appraisal of, the average doctor $[11,17,18]$. It is recommended that funding for both the appraiser, and the appraisal time itself, is included in any budget programme for GPwSI services. This budget should also take account of the necessity for continued professional development, training and interim developmental support.

\section{Conclusion}

Although GPwSI appraisal is not a mandatory requirement at the current time, we believe that the appraisal process will play an integral part in encouraging professional development of the GPwSI and hence in maximising the impact of the practitioner and the service on local health care. This 
process will be maximised by the proposed system for appraisal and developmental support outlined in our paper. The GPwSI appraisal will link closely to NHS GP appraisal and future plans for revalidation. It will complement, and be sensitive to, the needs of the GPwSI in respiratory medicine, and will enhance the professional role of the doctor. We believe that the quality-assured mechanism described above will allow the profession, NHS managers, and the public, to have the confidence that those GPwSls working in respiratory medicine will provide high quality care.

\section{Acknowledgement}

The authors would like especially to thank $\mathrm{Dr}$ Richard Russell (British Thoracic Society) and Dr Nick Lyons (National Association of Primary Care Educators/Modernisation Agency) for help and advice in the production of this document.

\section{References}

[1] Department of Health. Appraisal for General Practitioners working in the NHS London (2002) www.doh.gov.u's gpappraisal.

[2] Calman K. A review of continuing pre fessinal a cerelopment in general practice. Reporc b/ the Enlei Medical Officar. Departmen of $A_{t}$ : lth. Lbricon (1998)

[3] Department or Health/Royal Colleg - f Uenelal Practitioners. Implementing a scheme for General Practitioners with special interests. DoH, London (2002).

[4] Department of Health. Guidelines for the appointment of general practitioners with specialist interest in the delivery of clinical services - Respiratory Medicine. DoH, London (2003).

[5] General Medical Council. The policy framework for revalidation. A position paper. GMC, London (2004).

[6] General Medical Council. Good Medical Practice GMC, London. (2003) www.gmc-uk.org.

[7] Department of Health. Appraisal for general practitioners working in the NHS. DoH, London. (2002) www.doh.gov.uk/gpappraisal.

[8] NHS Education for Scotland. Appraisal for general practitioners working in Scotland. NHSES, Edinburgh (2003) www.nes.scot.nhs.uk.

[9] Smith J Dame. Fifth Report of the Shipman Inquiry: Safeguarding Patients: Lessons from the Past- Proposals for the Future. (2004) www.the-shipman-inquiry.org.uk.

[10] Caesar S. ABC Series of GP appraisal: Selection of Appraisers. NATPACT/NAPCE (2004) http://www.natpact.nhs.uk/ $\mathrm{cms} / 380$.php.

[11] Lyons N. Quality standards for GP appraisal. A report for the quality unit of the RCGP by National Association of Primary Care Educators (UK) RCGP, London (2003).

[12] Howard J. ABC Series of GP appraisal: Quality Assurance in Practice. NATPACT/NAPCE (2004) http://www.natpact.nhs.uk/cms/380.php.

[13] Holmes SGT. ABC Series of GP appraisal: Evaluation of Appraisal Process. NATPACT/NAPCE (2004) http://www. natpact.nhs.uk/cms/380.php.

[14] Gruffydd-Jones K. A proposal for the process of accreditation by portfolio for a GPwSI in resrifidtorv nedicine. Prim Care Respir J 2004:11 (1):13-20.

[15] Taylor B. Avorkirg with Others. York: Oasis Publications; 1:92.

110] Hay J. Transform actiol hentoring. New York: McGraw Hill; 1095 h 1012 Ul Mentoring. New York: McGraw Hill;

[1?] A =rintin D et al. Appraisal for GPs - A report from School of Health Related Research. University of Sheffield (ScHARR), Sheffield (2001).

[18] Smith F, Singleton A, Hilton S. General practitioners' continuing education: a review of policies, strategies and effectiveness and their implications for the future. $\mathrm{Br} \mathrm{J} \mathrm{Gen}$ Pract 1998;48:1689-95.

Available online at www.sciencedirect.com

science $\mathcal{W}$ direct.

Available online at http://www.thepcrj.com 